\title{
KNOWLEDGE OF MODIFIABLE RISK FACTORS OF HEART DISEASE AMONG PATIENTS WITH CARDIOVASCULAR RISK
}

\author{
ANDHUVAN G*, AYYAPPAN P, SAHANA C, POOVIZHI S, SIVASAKTHI K
}

Department of Pharmacy Practice, PSG College of Pharmacy, Coimbatore, Tamil Nadu, India. Email: visitandhuvan@yahoo.com

Received: 19 July 2016, Revised and Accepted: 21 September 2016

\section{ABSTRACT}

Objectives: Cardiovascular disease (CVD) is one of the leading killer diseases of people around the world. The purpose of this study was to examine the CVD risk factor and perception among individuals with high CVD risk.

Methods: An observational study was conducted for 6 months in the Department of General Medicine of a Multi-Specialty Hospital. Patients who were hypertensive, diabetic, and dyslipidemia with/without comorbid disease were included. Patients who are seriously ill, mentally retarded, physical disabilities, history of CVD, etc., were excluded. CVD risk assessment was done using Framingham risk score, and knowledge assessment was done using knowledge questionnaire on CVD risk. Patient counseling was given to the patients based on their risk and knowledge level and also to improve knowledge about CVD risk and therapeutic goals for the control of blood pressure, blood glucose, lipid profile, and smoking cessation.

Results: A total of 100 patients were included in this study comprising 46 males and 54 female. Male has more risk than female. The factors, viz., age, smoking habits, high cholesterol, and diabetes mellitus showed a greater risk in CVD. Knowledge levels assessed in those patients are $28 \%$ patients having poor knowledge, $30 \%$ patients having fair knowledge, and $42 \%$ patients having good knowledge.

Conclusion: The study concluded that the participants showed poor knowledge in CVD, which could turn into insufficient preventative behaviors and suboptimal patient outcomes. Pharmacist implementation is needed to assess CVD risk and to improve the health-related quality of life.

Keywords: Cardiovascular disease risk, Framingham risk score, Knowledge questionnaire.

(C) 2017 The Authors. Published by Innovare Academic Sciences Pvt Ltd. This is an open access article under the CC BY license (http://creativecommons. org/licenses/by/4. 0/) DOI: http://dx.doi.org/10.22159/ajpcr.2017.v10i1.14180

\section{INTRODUCTION}

Cardiovascular disease (CVD) is one of the leading killer diseases of people around the world. coronary artery disease accounts for $42 \%$ in males and $25 \%$ in females and higher in people with other complications. It is one of the chief diseases that have lead to premature death in Western countries. It is expected that, by 2030, 23.3 million people will die due to CVD.

In India, 2.4 millions of people die every year due to heart disease as per Health Care Foundation of India. According to recent data $25-30 \%$ of the urban population and $15 \%$ of the rural population suffer from CVD and its risk factors. Above all the most important factor is that every year 130,000 children in India are born with congenital heart disease due to lack of awareness among the population

CVD are a group of diseases which involve the heart or blood vessels that pass through the heart. CVD includes coronary artery disease (angina and myocardial infarction), stroke, and rheumatic heart disease, congenital heart disease, deep vein thrombosis, and peripheral artery disease [8].

There are several risk factors which include age, gender, tobacco use, physical inactivity, excessive alcohol consumption, unhealthy diet, obesity, family history of CVD, raised blood pressure (Hypertension), raised blood sugar (diabetes mellitus), raised blood cholesterol (Hyperlipidemia), psychological factors, and advancing age $[4,10,18]$.

The cardiovascular risk factors are divided into two major classifications.

Nonmodifiable risk factors and modifiable risk factors

Nonmodifiable risk factors are age, sex and family history, and modifiable risk factors are smoking, alcohol intake, diabetes mellitus, hypertension, hyperlipidemia, obesity, diet, physical inactivity, and stress.
According to a survey which is conducted by the British Heart Foundation among 2000 people only $2 \%$ have the awareness of heart disease, and the rest lacked knowledge of CVD. Almost one in five people (19\%) did not know Coronary Heart Disease (CHD) can be caused by smoking and $50 \%$ of adults did not know that diabetes can also lead to CVD. CHD kills 73,000 people a year on average one every seven minutes

The report suggests that 2.4 million Indians die every year due to CVD. The Health Care Foundation of India reports that the number continues to increase due to stress, physical inactivity, poor diet, lack of sleep, and finally dependence of alcohol and tobacco [10].

The need to create awareness about CVD and its preventive factors among the population is very important at present. Major primary prevention requires an effective assessment of risk to categorize patients for the selection of appropriate intervention [8]. Framingham Heart Study is a risk assessment tool to predict a chance for a person to get heart disease for the next 10 years. It is commonly used algorithm to predict the risk of coronary artery diseases. It is particularly designed for adults of 20 and older patients who are not having heart disease [3]. In this tool, the following details are included which plays a major role age, gender, total cholesterol, high-density lipoprotein-cholesterol (HDL-C), smoker, systolic blood pressure, and diabetes mellitus [6,11,16,17,19].

It is the duty of the pharmacist to give an effective awareness regarding CVD and its risk factors among the population. Pharmacists should take advantage of available resources to constantly build the essential skills and knowledge of patients. Thus, pharmacists provide a unique role in the delivery of health care $[1,2,4,6,7,9,13]$.

\section{METHODS}

An observational study was conducted in a multispecialty hospital. The ethical approval obtained from Institutional Human Ethics Committee. 
The study subjects were inpatients who are hypertensive, diabetic, and dyslipidemia with/without co-morbid disease conditions, who visited Department of General Medicine of PSG hospital Coimbatore, India. The study was conducted for months. Initial screening was performed based on inclusion and exclusion criteria. Patients who are seriously ill, mentally retarded, suffering from physical disabilities, history of CVD etc., were excluded from the study. Cardiovascular risk assessment was done using the Framingham Risk Score from that risk are categorized as high, moderate, and low and knowledge assessment was done using knowledge questionnaire about CVD risk. Patient counseling was given to the patients according to their risk and knowledge level. The primary goal is to achieve improvement of knowledge about CVD risk and therapeutic goals for control of blood pressure, blood glucose, lipid profile, and smoking cessation.

Statistical analysis was performed using SPSS 19.0 version. Categorical variables were described by frequencies and percentages. Association between demographic characteristics and cardiovascular risk was carried out using Pearson Chi-square test and positive and negative relationships were got using Pearson correlation. The student $t$-test (between study groups) was used to compare and mean values at $95 \%$ confidence intervals were also estimated.

\section{RESULT}

In this study, factors - such as the age, gender, smoking, elevated levels of total cholesterol, systolic blood pressure, and diabetes - were assessed to be the major risk factors. The demographic variables of samples which are categorized as age, gender, smoking habit, employment status, and diabetes mellitus are presented in Table 1 , and the majority of patients $(\mathrm{n}=39,39 \%)$ fell in 51-60 years categories. In addition, the study noted patient with co-morbidity condition, COPD $(n=8)$, UTI $(n=10)$, hyperlipidemia $(n=17)$, respiratory tract failure $(n=6)$, hypertension $(\mathrm{n}=18)$, chronic kidney disease $(\mathrm{n}=6)$, hypoglycemia( $\mathrm{n}=5)$ patients, and others $(n=30)$.

The risk assessment of male and female samples results was categorized into low, moderate, and high level using the Framingham risk scale. Out of 46 males, the majority of patients $(n=31,67 \%)$ fall in the high-risk category whereas in females $(n=54)$ and the majority of patients $(n=35$, $65 \%$ ) fall in the low-risk category, as illustrated in Table 2.

The knowledge assessment of CVD risk patients was done using questionnaires. The knowledge level was categorized as good, fair, poor, as illustrated in Table 3. Both males and females have adequate knowledge. Specifically, the patients were having poor knowledge on diabetes and cholesterols.

Only 25 patients answered for $1^{\text {st }}$ question relevantly. 75 patients answered correctly for $3^{\text {rd }}$ and $7^{\text {th }}$ questions, pertaining to the relationship between the age and CVD risk and that of between blood pressure and CVD risk. The patients were having good knowledge on that.

Average patients answered correctly for $2^{\text {nd }}, 4^{\text {th }}, 5^{\text {th }}$, and $8^{\text {th }}$ questions, pertaining to family history, smoking, and cholesterol. Hence, the patients have average knowledge about family history, smoking, and high cholesterol.

The statistical analysis used for the purpose was student $t$-test, Chisquare test, and Pearson correlation for finding association between demographic variables with knowledge. The study identified that there is a relationship between gender and risk which was significant $\left({ }^{*} \mathrm{p}=0.01\right)$ (Tables 4 and 5) and also stating that males are more prone to CVD risk as compared to females and it was further confirmed via $t$-test $\left({ }^{*} \mathrm{p}=0.01\right)$ as illustrated in Table 6 .

The study revealed the positive relation between age and risk and it was significant at a level of 0.01 (Tables 4 and 5) and in student $t$ - test were compared $>60$-year-old patients with $<60$-year-old patient and found that $>60$-year-old patient have more chance compared to $<60$-year-old patients, as represented in Table 6.

The result was positive and significant relationship between smoking and risk $\left({ }^{*} \mathrm{p}=0.01\right)$ and using student $t$-test also confirm that smokers have more CVD risk as compared to a non-smoker.

Table 1: Demographic variables of the samples

\begin{tabular}{ll}
\hline Variables & Number of patients (\%) \\
\hline Gender & \\
Male & $46(46)$ \\
Female & $54(54)$ \\
Age category & \\
$30-40$ & $8(8)$ \\
$41-50$ & $16(16)$ \\
$51-60$ & $39(39)$ \\
$61-70$ & $24(24)$ \\
$71-79$ & $13(13)$ \\
Smoking habit & $36(36)$ \\
Smokers & $64(64)$ \\
Non smokers & \\
Employment status & $41(41)$ \\
Employed & $59(59)$ \\
Unemployed & \\
Diabetic status & $89(89)$ \\
Diabetic & $11(11)$ \\
Non diabetic & \\
Education & $28(28)$ \\
Primary & $41(41)$ \\
Secondary & $19(19)$ \\
Higher secondary & $12(12)$ \\
Under graduate &
\end{tabular}

Table 2: Distribution of risk in samples

\begin{tabular}{lll}
\hline Risk category & Number of male (\%) & Number of Female (\%) \\
\hline Low & $4(9)$ & $35(65)$ \\
Moderate & $11(24)$ & $15(28)$ \\
High & $31(67)$ & $4(7)$ \\
\hline
\end{tabular}

Table 3: Distribution of knowledge among samples

\begin{tabular}{lll}
\hline Knowledge category & $\begin{array}{l}\text { Number of males } \\
\text { (\%) }\end{array}$ & $\begin{array}{l}\text { Number of females } \\
\text { (\%) }\end{array}$ \\
\hline Good & $18(39)$ & $24(44.4)$ \\
Fair & $16(35)$ & $14(26)$ \\
Poor & $12(26)$ & $16(29.6)$ \\
\hline
\end{tabular}

Table 4: Chi-square tests found relationship between variable and risk, relationship between variables and knowledge

\begin{tabular}{lll}
\hline Variables & DF & significant value (p value) \\
\hline Gender and risk & 51 & $<0.001$ \\
Age and risk & 612 & 0.001 \\
Smoking and risk & 34 & $<0.001$ \\
Total cholesterol and risk & 1037 & 0.055 \\
HDL and risk & 629 & $<0.001$ \\
Diabetes and risk & 16 & 0.003 \\
SBP and risk & 170 & 0.001 \\
Education and risk & 35 & 0.025 \\
Co-morbidities and risk & 51 & 0.66 \\
Age and knowledge & 72 & 0.09 \\
Gender and knowledge & 6 & 0.47 \\
Education and knowledge & 4 & $<0.001$ \\
\hline
\end{tabular}

HDL: High-density lipoprotein 
Table 5: Pearson correlation found positive and negative relationship between variable and risk, and variables and knowledge

\begin{tabular}{lll}
\hline Variables & Correlation & $\begin{array}{l}\text { Significant value } \\
\text { (p value) }\end{array}$ \\
\hline Gender and risk & -0.721 & $<0.001$ \\
Age and risk & +0.550 & $<0.001$ \\
Smoking and risk & +0.665 & $<0.001$ \\
Total cholesterol and risk & +0.143 & 0.155 \\
HDL and risk & -0.105 & 0.298 \\
Diabetes and risk & +0.268 & 0.007 \\
SBP and risk & +0.405 & $<0.001$ \\
SBP and risk & +0.405 & $<0.001$ \\
Education and risk & -0.259 & 0.009 \\
Co-morbidities and risk & +0.101 & 0.316 \\
Age and knowledge & +0.614 & $<0.001$ \\
Gender and knowledge & +0.17 & 0.866 \\
Education and knowledge & +0.697 & $<0.001$ \\
\hline
\end{tabular}

-: Represent negative relationship, +: Represent positive relationship, HDL: High-density lipoprotein

Table 6: Student $t$-test

\begin{tabular}{llll}
\hline Variables & Df & $\begin{array}{l}\text { 95\% confidence interval } \\
\text { of the difference }\end{array}$ & p \\
\hline Male & 44 & $22-27$ & $<0.001$ \\
Female & 56 & $6-10$ & $<0.001$ \\
Age $<60$ years & 41 & $19-25$ & $<0.001$ \\
Age $>60$ years & 59 & $7-13$ & \\
Smoker & 36 & $7-12$ & \\
Non smoker & 64 & $21-27$ & \\
\hline
\end{tabular}

The study summarized a positive relationship between total cholesterol and risk but it was not found to be significant $\left.{ }^{*} \mathrm{p}=0.155\right)$ and found a negative relationship between HDL since as HDL decreases, risk increases and it was not found to be significant $\left({ }^{*} \mathrm{p}=0.298\right)$.

The study reported a positive relationship between diabetes and risk and it says that as diabetes increases risk will also increase and it was found in significant $\left({ }^{*} \mathrm{p}=0.007\right)$. A positive relationship between SBP and risk, as SBP increases risk will also increase, it was significant $\left({ }^{*} \mathrm{p}=0.01\right)$ in this study [Tables 4 and 5$]$.

It observed a negative relationship between education and risk and it says that patients with less education have more risk and it was found to significant $\left({ }^{*} \mathrm{p}=0.01\right)$.

The positive relationship between comorbidities and risk representing when comorbidities increases risk will also increase but it was not found to be significant $\left({ }^{*} \mathrm{p}=0.316\right)$.

There was a negative relationship between age and knowledge. The elderly people have less knowledge about CVD and it was significant $\left({ }^{*} \mathrm{p}=0.01\right)$. The study found a positive relationship between education and knowledge. People with more knowledge about CVD were found to be significant at a level of 0.01 , represented in Table 5 .

\section{DISCUSSION}

This study mainly focuses on CVD risk patients with or without comorbid conditions. The observational study was conducted for 6 months in a multispecialty hospital to explore two main objectives, i.e., cardiovascular risk assessment on vulnerable patients and of their knowledge about CVD risk factors.

According to WHO, by 2030, almost 25 million people will die from CVDs. CVD risk factor awareness and knowledge are believed to be prerequisites for adapting lifestyle behavior.
Out of the assessment made males have a higher risk than females. A similar report was found in Fall et al. [3] which stated that they observed larger regression coefficients in men than in women for associations of BMI with systolic and diastolic blood pressure and levels of total cholesterol, triglycerides, alkaline transaminase, gama glutamate transaminase, and fasting insulin. Hence, men may have more risk than women.

While assessing and comparing the risk and age factors, the patients of age $>60$ years get more chance of CVD risk than in less than 60 years old patients and it was significant $(\mathrm{p}=0.001)$. The following study shows the findings of this study: Grundy et al. [18] stated that one of the more prominent features of the Framingham risk scoring is the progressive increase in absolute risk with advancing age. This increase undoubtedly reflects the cumulative nature of atherosclerosis. With advancing age, people typically accumulate increasing amounts of coronary atherosclerosis.

Our study brings out the fact that high total cholesterol and low HDL influence the risk rate of CVD. However, significant level was not found.

The study findings show relationship between SBP and risk. As SBP increase, the risk will also increase and it was significant at the level of 0.01

Grundy et al. [18] stated that the major and independent risk factors for CHD are cigarette smoking of any amount, elevated blood pressure, elevated serum total cholesterol and low-density lipoprotein cholesterol (LDL-C), low serum HDL-C, diabetes mellitus, and advancing age.

The study shows that a positive relationship between smoking and risk and also found it was significant at the level of 0.01 . Hence, smokers are more prone to CVD risk as compared to nonsmokers.

The study observed a significant finding in smoking and nonsmoker These results can be interpreted as evidence for the fact that the smoker gets more risk compared to nonsmoker. Similar to our findings, Eriksson et al. [15] stated that the effect of smoking reduction and smoking cessation resulted in clinically significant improvements in established cardiovascular risk factors. These improvements were even greater after an additional period of abstinence from smoking.

This study shows that the relationship between diabetes and CVD risk was significant $(\mathrm{p}=0.01$.) Chamnan et al., 2009 [12] \& Fox CS et al, 2008 [14], people with type 2 diabetes have an increased risk of CVD. Multivariate cardiovascular risk scores have been used in many countries to identify individuals who are at high risk of CVD. These risk scores include those originally developed for individuals with diabetes and those developed in a general population.

The study findings show a positive relationship between education and knowledge was significant ( $\mathrm{p}=0.01)$ Awad and Al-Nafisi 2014 [5] stated that in the current survey, gender, age, level of education, eating a healthy diet, and family history of CVD were found to be significantly associated with CVD knowledge $(\mathrm{p}<0.05)$. Knowledge about CVD was significantly higher among females compared to males.

Limitation of the study is short duration, and there is not enough time to conduct follow-up. Sample sizes were small. A larger sample size is more representative of the population. The number of observations is small study can fail to produce sensible results or they produce unreliable results.

The Framingham Risk Score predicts only future CHD events; however, it does not predict a future total cardiovascular event, i.e., does not predict risk for stroke, transient ischemic attack, and heart failure.

According to our study, 35\% patients have high and 26\% patients having moderate CVD risk. CVD risk factors are shown the correlation of cardiovascular disease. 


\section{CONCLUSION}

The study concluded that the study participants showed deficiency in CVD knowledge, which could turn into insufficient preventive behaviors and suboptimal patient outcomes. Pharmacists being active members of the health care team can play an important role in providing patient counseling so as to reduce cardiovascular risk factors, drug related problems and also to improve therapeutic outcomes along with healthrelated quality of life.

\section{REFERENCES}

1. Priya JK, Balambigai MS, Sariga N, Sathya M, Andhuvan G. Development and validation of patient information leaflet for heart attack patients. Int J Pharm Pharm Sci 2016;8(8):381-3.

2. Kounelis AP. Pharmacists Role in Cardiovascular Disease Management - 13 August; 2015. Available from: http://www. knowledgedriven.com/articles/pharmacies/a-pharmacist's-role-incardiovascular-disease-risk-management.aspx\#.VgD-hN-qqko.

3. Fall T, Hägg S, Ploner A, Mägi R, Fischer K, Draisma HH, et al. Age - And sex-specific causal effects of adiposity on cardiovascular risk factors. Diabetes 2015;64:1841-52.

4. Andhuvan G, Venkatachalam VV, Sankar V. Impact of pharmacist education on medication adherance in heart failure patients. Int J Pharm Pharm Sci 2014;6(11):474-6.

5. Awad A, Al-Nafisi H. Public knowledge of cardiovascular disease and its risk factors in Kuwait: A cross-sectional survey. BMC Public Health 2014; $14: 1131$.

6. D'Agostino RB Sr, Pencina MJ, Massaro JM, Coady S. Cardiovascular disease risk assessment: Insights from Framingham. Glob Heart 2013;8(1):11-23.

7. Altowaijri A, Phillips CJ, Fitzsimmons D. A systematic review of clinical and economic effectiveness of clinical pharmacist intervention in secondary prevention of cardiovascular disease. J Manag Care Pharm 2013;19(5):405-16.

8. IANS. Modified: World Health Day 2014: Is India staring at a heart disease epidemic? Diabetes Care 2012;35:334-41.

9. Talasaz AH. The potential role of clinical pharmacy services in patients with cardiovascular diseases. J Tehran Univ Heart Cent 2012;7(2):41-6

10. Mullie P, Clarys P. Association between cardiovascular disease risk factor knowledge and lifestyle. Food Nutr Sci 2011;2(10):1048-53.

11. Bitton A, Gaziano TA. The Framingham Heart Study's impact on global risk assessment. Prog Cardiovasc Dis 2010;53(1):68-78.

12. Chamnan P, Simmons RK, Sharp SJ, Griffin SJ, Wareham NJ Cardiovascular risk assessment scores for people with diabetes: A systematic review. Diabetolgia 2009;52(10):2001-14.

13. Santschi V, Chiolero A, Burnand B, Colosimo AL, Paradis G. Impact of pharmacist care in the management of cardiovascular disease risk factors: A systematic review and meta-analysis of randomized trials. Arch Intern Med 2011;171(16):1441-53.

14. Fox CS, Pencina MJ, Wilson PW, Paynter NP, Vasan RS, D’Agostino RB Sr. Lifetime risk of cardiovascular disease among individuals with and without diabetes stratified by obesity status in the Framingham Heart Study. Diabetes Care 2008;31(8):1582-4.

15. Eriksson KM, Westborg CJ, Eliasson MC. A randomized trial of lifestyle intervention in primary healthcare for the modification of cardiovascular risk factors. Scand J Public Health 2006;34(5):453-61.

16. Conroy RM, Pyörälä K, Fitzgerald AP, Sans S, Menotti A, De Backer G, et al. Estimation of ten-year risk of fatal cardiovascular disease in Europe: The SCORE project. Eur Heart J 2003;24(11):987-1003.

17. D'Agostino RB Sr, Grundy S, Sullivan LM, Wilson P; CHD Risk Prediction Group. Validation of the Framingham coronary heart disease prediction scores: Results of a multiple ethnic groups investigation. JAMA 2001;286(2):180-7.

18. Grundy SM, Pasternak R, Greenland P, Smith S Jr, Fuster V. Assessment of cardiovascular risk by use of multiple-risk-factor assessment equations. A statement for healthcare professionals from the American Heart Association and the American College of Cardiology. J Am Coll Cardiol 1999;34(4):1348-59.

19. Wilson PW, D'Agostino RB, Levy D, Belanger AM, Silbershatz H, Kannel WB. Prediction of coronary heart disease using risk factor categories. Circulation 1998;97(18):1837-47. 